\title{
The relationship between perceived stress and problematic social networking site use among Chinese college students
}

\author{
XIANG-LING HOU ${ }^{1}$, HAI-ZHEN WANG ${ }^{2}$, TIAN-QIANG HU ${ }^{1}$, DOUGLAS A. GENTILE ${ }^{3}$, JAMES GASKIN ${ }^{4}$ and \\ JIN-LIANG WANG ${ }^{1 *}$ \\ ${ }^{1}$ Center for Mental Health Education, School of Psychology, Southwest University, Chongqing, China \\ ${ }^{2}$ Department of Tourism and Art for Humanity, Chongqing Youth and Vocational Technical College, Chongqing, China \\ ${ }^{3}$ School of Psychology, Iowa State University, Ames, IA, USA \\ ${ }^{4}$ Department of Information System, Brigham Young University, UT, USA
}

(Received: November 29, 2018; revised manuscript received: April 10, 2019; accepted: April 21, 2019)

\begin{abstract}
Background and aims: Perceived stress has been regarded as a risk factor for problematic social networking site (SNS) use, yet little is known about the underlying processes whereby confounding variables may mediate or moderate this relationship. To answer this question, this study examined whether depression and anxiety mediated the relationship between perceived stress and problematic SNS use, and whether these mediating processes were moderated by psychological resilience and social support. Methods: Participants were 641 Chinese college students who completed anonymous questionnaires measuring perceived stress, depression/anxiety, psychological resilience, social support, and problematic SNS use. Results: The results showed that (a) depression/anxiety mediated the relationship between perceived stress and problematic SNS use; (b) the mediating effects of depression/anxiety on the association between perceived stress and problematic SNS use were moderated by psychological resilience. Specifically, the mediating effects of depression/anxiety were stronger for individuals with lower levels of psychological resilience, compared with those with higher levels of psychological resilience; and (c) the mediating effects of depression/anxiety were not moderated by social support, although social support was negatively related to depression/anxiety. Discussion and conclusion: This study can contribute to a better understanding of how and when perceived stress increases the risk of problematic SNS use, and implies the importance of enhancing psychological resilience in preventing problematic SNS use.
\end{abstract}

Keywords: perceived stress, depression/anxiety, psychological resilience, social support, problematic SNS use

\section{INTRODUCTION}

Social networking sites (SNSs) have increased inpopularity due to the development of mobile 4G technology and the wide adoption of smartphones. SNSs have become an important platform for sharing information as well as establishing and maintaining relationships (Song et al., 2014). In the US and Europe, SNS such as Facebook, Twitter, and LinkedIn are among the top popular, and in China people mostly use WeChat, Weibo, and Renren. In China, 90\% of college students are active users of WeChat ( $\mathrm{Li}$, Wang, Lu, Wang, \& Zhu, 2016). To a very large extent, WeChat has penetrated into Chinese college students' lives and has become an indispensable tool.

Prior studies have shown that college students can benefit from using SNS, for example, SNS use not only is positively related to subjective well-being (Wang, Jackson, Gaskin, \& Wang, 2014), but also can enhance self-esteem (Gonzales \& Hancock, 2011). More recent research, however, cautioned that spending too much time on SNS may lead to problematic and even addictive symptom-like behaviors (e.g., Brailovskaia, Schillack, \& Margraf, 2018). Researchers have used several terms to describe these problem behaviors, including problematic SNS use, SNS addiction, and overuse of SNS (Kuss \& Griffiths, 2011; Wu, Cheung, Ku, \& Hung, 2013). Although different authors use different terms (Ryan, Chester, Reece, \& Xenos, 2014), they tend to agree on the underlying essence - use that is ultimately dysfunctional. In this study, we use the term "problematic SNS use," and adopt Huang, Hsieh, and Wu's (2014) definition: (a) maladaptive preoccupation with SNS use, experienced as irresistible use for periods of time longer than intended; and (b) distress or impairment resulting from such behavior. Researchers have reported that problematic SNS use is detrimental to students' mental health and academic performance (Turel \& Qahri-Saremi, 2016), and is positively related to decreased subjective well-being (Satici \& Uysal, 2015) and increased loneliness (Ndasauka et al., 2016). As problematic SNS use has a significant * Corresponding author: Jin-Liang Wang; Center for Mental
Health Education, School of Psychology, Southwest University,
No. 2 Tiansheng Road, BeiBei District, Chongqing 400715, China; Phone: +86 1573027 7936; E-mail: wangjinliang09@gmail.com

This is an open-access article distributed under the terms of the Creative Commons Attribution-NonCommercial 4.0 International License, which permits unrestricted use, distribution, and reproduction in any medium for non-commercial purposes, provided the original author and source are credited, a link to the CC License is provided, and changes - if any - are indicated. 
impact on students' mental health, studying the antecedents of problematic SNS use and the psychological mechanism whereby problematic SNS use occurs prove to be extremely important (e.g., Brailovskaia, Schillack, et al., 2018; Kuss \& Griffiths, 2011). University students frequently experience many kinds of stress such as academic stress (Arnett, 2000); some of them might excessively use SNS to find relief and to escape from negative affect (e.g., depression and anxiety) after stressful experiences (e.g., Kardefelt-Winther, 2014; Ryan et al., 2014). As such, perceived stress might be the primary predictor of problematic SNS use and depression/ anxiety might be the mediators in this relationship. However, most people who experience stressful events do not develop such negative emotions, raising the question of which factors provide protection. Psychological resilience (e.g., Anyan \& Hjemdal, 2016; Garmezy, Masten, \& Tellegen, 1984) and social support (e.g., Cohen \& Wills, 1985), on the other hand, have been found to buffer the influence of stress. That is, psychological resilience and social support might play significant roles in the mediating effects of depression and anxiety.

Therefore, this study aimed to establish a moderated mediation model to test whether depression and anxiety mediate the relation between perceived stress and problematic SNS use, and whether these mediating effects are moderated by psychological resilience and social support. This method offers a more comprehensive picture by elucidating specific mechanisms by which exposure to stress is related to problematic SNS use and by identifying the individuals who may be more susceptible to such problems when exposed to similar experiences. Moreover, the results of this study will help university administrators and psychological practitioners to design interventions for students who are engaging in problematic SNS use by highlighting the importance of increases in psychological resilience and social support as well as reductions in negative affect including depression and anxiety.

The relationship between perceived stress and problematic SNS use

Among the factors that may influence problematic SNS use, perceived stress is one important variable that has attracted researchers and mental health practitioners' attention (e.g., Brailovskaia, Teismann, \& Margraf, 2018; Hou et al., 2017). Perceived stress is defined as a situation that individuals evaluate as threatening or otherwise demanding and for which they lack sufficient resources to address (Cohen, Kamarck, \& Mermelstein, 1983). Perceived stress is positively related to increased depression symptoms and suicide ideation (Anastasiades, Kapoor, Wootten, \& Lamis, 2017), and poorer sleep quality (Wallace, Boynton, \& Lytle, 2017). University life can be stressful due to experiences of academic failure, moving away from home, separating from family members, and changes in friendship relations (Borjalilu, Mohammadi, \& Mojtahedzadeh, 2015). To cope with stress in their lives, some students may choose to deal with problems passively, like spending a lot of time online to avoid their problems (Chen, Poon, \& Cheng, 2017). Perceived stress is closely related to Internet-relevant problematic behaviors, such as Internet addiction
(Chen et al., 2017), smartphone addiction (Samaha \& Hawi, 2016), and Facebook addiction disorder (Brailovskaia \& Margraf, 2017). In a recent study, perceived stress was found to be related to problematic SNS use (Hou et al., 2017). In another, students who had higher anxiety and specifically used video games as a method to cope with their stress showed higher Internet gaming disorder symptoms (Plante, Gentile, Groves, Modlin, \& Blanco-Herrera, 2018).

Despite the reported link between perceived stress and problematic SNS use, the mechanism underlying this link is yet not well known (e.g., Brailovskaia, Teismann, et al., 2018). For instance, Hou et al. (2017) recently found that psychological resilience moderated the relationship between perceived stress and problematic SNS use. However, there is still a lack of systematic study about mediating mechanisms and any moderated mediation effects in this relationship. This has hindered a deep understanding of the relationship between perceived stress and problematic SNS use. The investigation into this question would help us understand how and when perceived stress influences problematic SNS use, which would also be helpful for designing effective interventions.

\section{The mediating roles of depression and anxiety between perceived stress and problematic SNS use}

Perceived stress can have a negative impact on individuals' neuroendocrine, cardiovascular, immune, and metabolic systems, and individuals experiencing high level of stress may be at a risk of developing negative emotions including depression and anxiety (Blaxton \& Bergeman, 2017; Watson \& Clark, 1984). Depression symptoms are dominated by the emotion of sadness and are associated with feelings of sorrow, hopelessness, and gloom. In contrast, anxiety symptoms are centered on the emotion of fear and involve feelings of worry, apprehension, and dread (Watson et al., 1995). Phenomenologically, depression and anxiety are clearly separate but often comorbid symptoms in youth (Kendall, Kortlander, Chansky, \& Brady, 1992; Watson et al., 1995). A large number of studies have proved that perceived stress is positively related to both depression and anxiety (e.g., Cole et al., 2015; Heinen, Bullinger, \& Kocalevent, 2017). Individuals experiencing high negative affect such as depression and anxiety tend to be in a continual state of distress or dissatisfaction regardless circumstances (Çivitci, 2015). Therefore, they are more likely to focus on the negative aspects of themselves as well as the negative aspects of others and the world they live in (Watson \& Pennebaker, 1989).

Additionally, since negative affect can influence individuals' control over their behaviors (Peng, Yang, \& Luo, 2013), depression and anxiety have been regarded as risk factors for many problematic behaviors. For example, both cross-sectional and longitudinal studies have shown that depression and anxiety are associated with substance use (Breslau, Novak, \& Kessler, 2004; Bujarski \& Ray, 2014; McKenzie, Olsson, Jorm, Romaniuk, \& Patton, 2010). Moreover, depression and anxiety are also positively related to behavioral addictions, including Facebook addiction disorder (Brailovskaia \& Margraf, 2017; Brailovskaia, Schillack, et al., 2018), Internet addiction (Kelley \& Gruber, 2010), and mobile phone dependence (Hong, Chiu, \& Huang, 2012). 
Furthermore, the compensatory Internet use theory argues that users may use Internet-connected devices excessively to deal with a negative mood or to escape their real-life problems (Kardefelt-Winther, 2014); it is reasonable to assume that depression and anxiety may mediate the relationship between perceived stress and problematic SNS use. Findings from other studies have also lent support to this assumption. For instance, depression and anxiety can mediate the association between stress and problematic behaviors such as eating disorder (Chen et al., 2012), marijuana use (Ketcherside \& Filbey, 2015), and Internet addiction (Zhao et al., 2017). Hence, we form our first hypothesis that depression and anxiety mediate the association between perceived stress and problematic SNS use $(H 1)$. To be specific, perceived stress is positively related to problematic SNS use via depression $(H 1 a)$ and anxiety $(H 1 b)$.

\section{The moderating roles of psychological resilience and social support}

Despite the possibility that perceived stress may lead to depression and anxiety, it is not universal that people would necessarily feel bad after experiencing stressful events (Beutel et al., 2017). Some psychological variables may protect individuals from the negative impacts of perceived stress. It has been proposed that protective factors include two categories, such as internal assets (e.g., psychological resilience) and external resources (e.g., social support; Min, Lee, \& Chae, 2015). In this study, we aimed to investigate whether psychological resilience and social support can buffer the impacts of perceived stress on individuals' depression and anxiety, which may further lead to less problematic SNS use.

Psychological resilience. Psychological resilience refers to an individual's capacity to deal with stress and develop adaptively in the face of adversity (Connor \& Davidson, 2003). Psychological resilience can help individuals cope with stress, adversity, and trauma effectively, and maintain their mental health (Hu, Zhang, \& Wang, 2015). People of higher psychological resilience are typically characterized by optimism, positive coping, and hardiness, and these characteristics might help individuals successfully cope with negative life events (Connor \& Davidson, 2003). Researchers have found that psychological resilience is positively related to psychological well-being (Kumar \& Singh, 2014), positive affect, and self-esteem (Smith, Tooley, Christopher, \& Kay, 2010), whereas being negatively related to negative mental health indices such as emotional and behavioral problems (Arslan, 2016) and emotional distress (i.e., depression and anxiety; Min et al., 2013).

Regarding the relations between psychological resilience and depression/anxiety, cross-sectional (Cole et al., 2015; Goldstein, Faulkner, \& Wekerle, 2013), longitudinal (Wu et al., 2017), and meta-analytic studies (Hu et al., 2015) have revealed that psychological resilience can protect individuals against depression and anxiety. Moreover, both the protective factor model (Garmezy et al., 1984) and the resilience-stress theory (Fletcher \& Sarkar, 2013; Masten, 2011) posit that when people encounter stressful or challenging life events, individuals' intrapersonal assets such as psychological resilience can be activated to help them cope with the situations and decrease negative appraisals of the stressful events. Psychological resilience was found to weaken the associations between risk factors (e.g., stress and trauma) and depression/anxiety (Anyan \& Hjemdal, 2016; Goldstein et al., 2013). For instance, Cole et al. (2015) reported that psychological resilience weakened the association between academic stress and college students' anxiety symptoms. In another study, participants who had experienced sexual and physical abuse in childhood but reported high levels of psychological resilience did not show anxiety and depression symptoms when they entered adulthood (Collishaw et al., 2007). Similarly, a randomized controlled trial of the Resilience and Coping Intervention (RCI) with undergraduate university students found RCI to be an effective group intervention, as RCI participants reported significantly more hope and less stress and depression from Week 1 to Week 3 compared to participants in the control group (Houston et al., 2017). Given this evidence, we hypothesize that psychological resilience moderates the links between perceived stress and depression/anxiety (H2). Specifically, the associations between perceived stress and depression $(H 2 a)$ as well as anxiety $(H 2 b)$ will be stronger for users with lower levels of psychological resilience than those with higher levels.

Social support. Social support refers to the degree to which individuals believe that family, friends, and others can be expected to provide material assistance, emotional relief, and information when necessary (Thoits, 2011). As an important component of external resource, social support has been consistently reported as a positive relationship with both physical and psychological health (Cohen, 1988; Schradle \& Dougher, 1985). Studies with college students have revealed negative associations between social support and depression/anxiety (e.g., Raffaelli et al., 2013; Sperry \& Widom, 2013; Wright, King, \& Rosenberg, 2014).

Furthermore, social support can improve individuals' capabilities to cope with stressful events by influencing their cognitions, emotions, behaviors, and physical responses (Cohen, 2004; Cohen, Underwood, \& Gottlieb, 2000; Klink, Byars-Winston, \& Bakken, 2008). According to the stress-buffering model, social support may mitigate the psychological impact of a stressful event on mental health by attenuating the stress appraisal response (Cohen $\&$ Wills, 1985). Individuals tend to rate the harmful effects of depression and anxiety lower if they perceive more social support, which may decrease their evaluations of the stressful events, which leads to less negative emotional responses (Park et al., 2013). Empirical studies have also shown that social support compensated or moderated the impacts of stressful events on their depression and anxiety (e.g., Raffaelli et al., 2013; Wang, Cai, Qian, \& Peng, 2014). Therefore, we hypothesize that social support moderates the links between perceived stress and depression/anxiety (H3). Specifically, the associations between perceived stress and depression $(H 3 a)$ as well as anxiety $(H 3 b)$ will be stronger for users perceiving less social support compared with those perceiving more.

\section{The present study}

This study examined the underlying mechanism whereby perceived stress was related to problematic SNS use among 


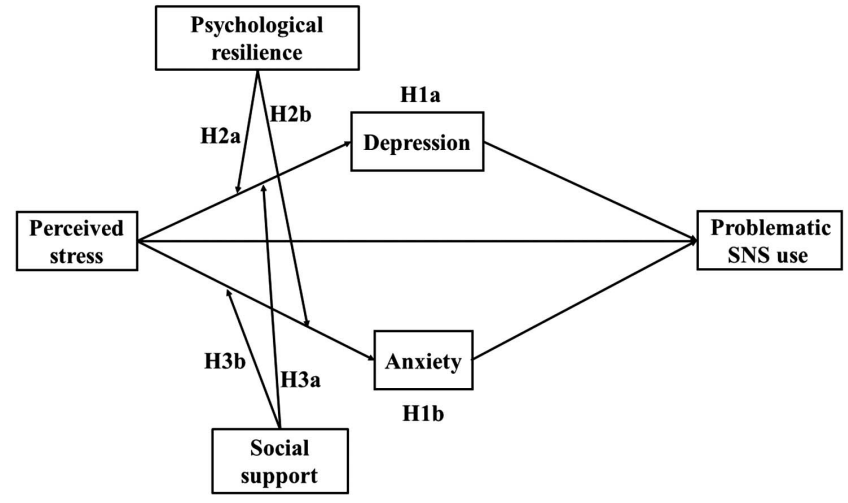

Figure 1. Conceptual moderated mediation model

Chinese college students. To be specific, this study aimed to answer two questions: (a) whether perceived stress influences problematic SNS use via the mediating roles of depression and anxiety and (b) whether these mediation effects would be moderated by psychological resilience and social support. Based on the aforementioned information, we hypothesize the research model called "moderated mediation" whereby psychological resilience and social support moderate the mediating effects of depression and anxiety (the first stage of the mediating processes was moderated; Edwards \& Lambert, 2007; Muller, Judd, \& Yzerbyt, 2005), which was illustrated in Figure 1.

\section{METHODS}

\section{Participants}

Participants were 641 college students (mean age $=19.90$ years, $S D=1.37 ; 74.4 \%$ females) from three universities in Chongqing, China, ranging in age from 17 to 25 years old. All reported having an active WeChat user account. Among them, 20.3\% were freshmen, 39.5\% were sophomores, $27 \%$ were juniors, and $13.3 \%$ were seniors. More than half $(59.8 \%)$ of the participants majored in natural science (math, physics, chemistry, biology, life sciences, and computer sciences) and $40.2 \%$ in social science (economics, business administration, education, philology, law, politics, and philosophy).

\section{Measures}

Six self-report questionnaires were used for data collection including the Perceived Stress Scale (PSS), the Center for Epidemiologic Studies Depression Scale (CES-D), the State Anxiety Subscale (S-Anxiety), the Connor-Davidson Resilience Scale (CD-RISC), the Perceived Social Support Scale (PSSS), and the Facebook Intrusion Questionnaire (FIQ).

Perceived stress. Perceived stress was measured by the PSS (Cohen et al., 1983), which assessed the stress and level of control that participants perceived over the past month. Participants answered 14 items (e.g., "In the last month, how often have you been upset because of something that happened unexpectedly?" and "In the last month, how often have you felt that you were unable to control the important things in your life?") on a 5-point scale ranging from 0 (never) to 4 (very often). As recommended by the originators of the scale (Cohen et al., 1983), all the items were summed to obtain a total score, with higher scores representing higher stress levels and a higher perceived lack of control. This scale has shown good reliability and validity in Chinese college students (Hou et al., 2017). In this study, the Cronbach's $\alpha$ for the construct was .73.

Depression. Depression was measured by the CES-D (Radloff, 1977), which assessed depressive symptoms during the past week and was used in the general population. Participants answered 20 items (e.g., "I was bothered by things that usually don't bother me" and "I did not feel like eating; my appetite was poor") on a 4-point scale ranging from 0 (rarely) to 3 (most or all of the time). The total score was achieved by summing all responses (as recommended by Roberts, Andrews, Lewinsohn, \& Hops, 1990), with higher scores representing severe depressive symptoms. In this study, the Cronbach's $\alpha$ for the construct was .85 .

Anxiety. Anxiety was measured by the S-Anxiety from State-Trait Anxiety Inventory (Spielberger, Gorsuch, \& Lushene, 1970), which assessed intensity of current feelings "at this moment." Participants answered 20 items (e.g., "I feel calm" and "I feel upset") on a 4-point scale ranging from 1 (not at all) to 4 (very much). The total score was achieved by summing all responses (as recommended by Spielberger et al., 1970), with higher scores representing greater anxiety. In this study, the Cronbach's $\alpha$ for the construct was .85 .

Psychological resilience. Psychological resilience was measured by the Chinese version of the CD-RISC ( $\mathrm{Yu} \&$ Zhang, 2007) developed by Connor and Davidson (2003). Participants answered 25 items (e.g., "Able to adapt to change" and "Can deal with whatever comes") on a 5-point scale ranging from 1 (not true at all) to 5 (true nearly all of the time). The total score was achieved by summing all responses (as recommended by Campbell-Sills et al., 2006), with higher scores representing greater psychological resilience. In this study, the Cronbach's $\alpha$ for the construct was .88 .

Social support. Social support was measured by the PSSS (Zimet, Dahlem, Zimet, \& Farley, 1988), which assessed perceptions of social support adequacy from family, friends, and significant others. Participants answered 12 items (e.g., "My family really tries to help me" and "I can count on my friends when things go wrong") on a 7-point scale ranging from 1 (very strongly disagree) to 7 (very strongly agree). Rather than using a total summated score (as with all other scales in this study), Zimmet et al. (1988) imply a two dimensional, formative second order, reflective first-order latent factor. In this study, the Cronbach's $\alpha$ for the construct was .92 .

Problematic SNS use. Problematic SNS use was measured by the FIQ (Elphinston \& Noller, 2011), which was modified by Hou et al. (2017). According to interviews with Chinese college students, they added two items to the original 8-item scale ("I often hide the time of using Weibo from my family and friends" and "I often use Weibo while doing other things, such as eating, attending class, etc."). For the purpose of this study, items were revised to fit the WeChat use (e.g., "I often think about WeChat when I am not using it" and "I often use WeChat for no particular 
reason"). Participants answered 10 items on a 5-point scale ranging from 1 (not at all true) to 5 (very true). The total score was achieved by summing all responses (as recommended by Elphinston \& Noller, 2011), with higher scores representing higher levels of problematic SNS use. In this study, the Cronbach's $\alpha$ for the construct was .88 .

\section{Procedure}

The survey was conducted in classrooms between October and November 2016. Participation was voluntary and anonymous. The data collectors were well-trained psychology graduate students. They explained to all participants the requirements of the questionnaires using standard instructions and emphasized the authenticity, independence, and integrity of all answers. If participants had any questions during the assessment, they could ask the data collectors. Meanwhile, participants were informed that they could decline to participate and were free to withdraw at any time. The questionnaires were collected immediately after they had finished. The average time for completing the measures was approximately $20 \mathrm{~min}$. Participants were not compensated for participating in the study.

\section{Statistical analysis}

SPSS 19.0 (IBM, Armonk, NY, USA) was used for our data analysis. Descriptive statistics and zero-order correlations were calculated for all variables. Then, a moderated mediation analysis was performed using PROCESS macro (Model 9; Hayes, 2013), which is specifically developed for testing the complex models including both mediators and moderators, and used in many related studies (e.g., Cole, Walter, \& Bruch, 2008; Wang et al., 2017). This method mainly estimated three parts: mediator variable model, dependent variable model, and conditional indirect effect analysis. In this study, the mediator variable model was to test the effects of perceived stress and psychological resilience/social support on depression/anxiety, whereas the dependent variable model was to test the effects of perceived stress and depression/anxiety on problematic SNS use. The conditional indirect effect analysis was applied to test the effects of perceived stress on problematic SNS use via depression/anxiety at different levels $(M \pm 1 S D)$ of psychological resilience/social support. Gender and age were controlled in the whole analysis, and all the predictors were standardized to minimize multicollinearity (Dearing \& Hamilton, 2006). The bootstrapping method was used to test for the significance of the effects so as to obtain robust standard errors for parameter estimation (Hayes, 2013). In this study, all the bootstrapping analyses produced $95 \%$ bias-corrected confidence intervals (CIs) of the effects from 5,000 resamples of the data. CIs do not span zero indicating the effects are significant.

\section{Ethics}

The study was approved by the Research Ethics Committee of Southwest University, Chongqing, China. The study was conducted after informed consent had been obtained from the schools, teachers, and participants.

\section{RESULTS}

\section{Data screening}

First, duplicate responses and regular responses (e.g., $1234512345 \ldots)$ as well as one or more scales with no response were removed from analyses $(n=8)$. Second, we examined univariate outliers by z-scores (i.e., above and less than 3) for each scale and dropped these $(n=13)$ from analyses (Osborne \& Overbay, 2004). Finally, skewness and kurtosis were examined for each variable (Table 1). According to Curran, West, and Finch (1996), the distribution of study variables showed no significant skewness $(<7)$ and kurtosis $(<2)$.

\section{Preliminary analyses}

Preliminary analyses for the study variables are presented in Table 1.

\section{Testing for moderated mediation effect}

The results generated by PROCESS macro are presented in Table 2 and Figure 2. The mediator variable model and dependent variable model showed that perceived stress was positively related to depression $(\beta=0.37, p<.001)$ and

Table 1. Descriptive statistics for study variables $(N=641)$

\begin{tabular}{|c|c|c|c|c|c|c|}
\hline & 1 & 2 & 3 & 4 & 5 & 6 \\
\hline 1. Perceived stress & - & & & & & \\
\hline 2. Depression & $0.45 * *$ & - & & & & \\
\hline 3. Anxiety & $0.37 * *$ & $0.68 * *$ & - & & & \\
\hline 4. Psychological resilience & $-0.45 * *$ & $-0.32 * *$ & $-0.30 * *$ & - & & \\
\hline 5. Social support & $-0.23 * *$ & $-0.29 * *$ & $-0.33 * *$ & $0.45^{* *}$ & - & \\
\hline 6. Problematic SNS use & $0.11 * *$ & $0.22 * *$ & $0.22 * *$ & 0.06 & 0.04 & - \\
\hline$M$ & 40.47 & 36.36 & 40.42 & 84.51 & 62.06 & 19.43 \\
\hline$S D$ & 4.95 & 8.75 & 7.89 & 10.27 & 10.46 & 7.14 \\
\hline Skewness & 0.27 & 0.67 & 0.27 & -0.10 & -0.52 & 0.61 \\
\hline Kurtosis & 0.55 & 0.82 & 0.02 & 0.49 & 0.63 & -0.29 \\
\hline
\end{tabular}

Note. SNS: social networking site; $S D$ : standard deviation.

$* * p<.01$. 
Table 2. Conditional process analysis (moderated mediation analysis; $N=641$ )

\begin{tabular}{|c|c|c|c|c|}
\hline & $\beta$ & $S E$ & $t$ & $p$ \\
\hline \multicolumn{5}{|l|}{ Mediator variable model } \\
\hline Gender & $0.01^{\mathrm{D}} / 0.15^{\mathrm{A}}$ & $0.08^{\mathrm{D}} / 0.08^{\mathrm{A}}$ & $0.05^{\mathrm{D}} / 1.85^{\mathrm{A}}$ & $.96^{\mathrm{D}} / .06^{\mathrm{A}}$ \\
\hline Age & $0.01^{\mathrm{D}} / 0.03^{\mathrm{A}}$ & $0.02^{\mathrm{D}} / 0.02^{\mathrm{A}}$ & $0.52^{\mathrm{D}} / 1.27^{\mathrm{A}}$ & $.60^{\mathrm{D}} / .20^{\mathrm{A}}$ \\
\hline Perceived stress & $0.37^{\mathrm{D}} / 0.27^{\mathrm{A}}$ & $0.04^{\mathrm{D}} / 0.04^{\mathrm{A}}$ & $9.42^{\mathrm{D}} / 6.74^{\mathrm{A}}$ & $<.001^{\mathrm{D}} /<.001^{\mathrm{A}}$ \\
\hline Psychological resilience & $-0.05^{\mathrm{D}} /-0.05^{\mathrm{A}}$ & $0.04^{\mathrm{D}} / 0.04^{\mathrm{A}}$ & $-1.26^{\mathrm{D}} /-1.24^{\mathrm{A}}$ & $.21^{\mathrm{D}} / .22^{\mathrm{A}}$ \\
\hline Perceived stress $\times$ Psychological resilience & $-0.09^{\mathrm{D}} /-0.08^{\mathrm{A}}$ & $0.04^{\mathrm{D}} / 0.04^{\mathrm{A}}$ & $-2.36^{\mathrm{D}} /-2.02^{\mathrm{A}}$ & $<.05^{\mathrm{D}} /<.05^{\mathrm{A}}$ \\
\hline Social support & $-0.17^{\mathrm{D}} /-0.24^{\mathrm{A}}$ & $0.04^{\mathrm{D}} / 0.04^{\mathrm{A}}$ & $-4.48^{\mathrm{D}} /-6.07^{\mathrm{A}}$ & $<.001^{\mathrm{D}} /<.001^{\mathrm{A}}$ \\
\hline Perceived stress $\times$ Social support & $0.02^{\mathrm{D}} /-0.02^{\mathrm{A}}$ & $0.04^{\mathrm{D}} / 0.04^{\mathrm{A}}$ & $0.45^{\mathrm{D}} /-0.68^{\mathrm{A}}$ & $.65^{\mathrm{D}} / .49^{\mathrm{A}}$ \\
\hline \multicolumn{5}{|l|}{ Dependent variable model } \\
\hline Gender & 0.02 & 0.09 & 0.25 & .80 \\
\hline Age & 0.14 & 0.03 & 5.23 & $<.001$ \\
\hline Perceived stress & 0.01 & 0.04 & 0.21 & .83 \\
\hline Depression & 0.14 & 0.05 & 2.58 & $<.05$ \\
\hline Anxiety & 0.12 & 0.05 & 2.38 & $<.05$ \\
\hline
\end{tabular}

Conditional indirect effects of depression and anxiety in the relationship between perceived stress and problematic SNS use at values of the moderator

$\begin{array}{cccccc} & & \text { Effect } & \text { Boot } S E & \text { Boot LLCI } & \text { Boot ULCI } \\ \text { Resilience } & M-1 S D & 0.06^{\mathrm{D}} / 0.04^{\mathrm{A}} & 0.03^{\mathrm{D}} / 0.02^{\mathrm{A}} & 0.01^{\mathrm{D}} / 0.01^{\mathrm{A}} & 0.12^{\mathrm{D}} / 0.09^{\mathrm{A}} \\ & M+1 S D & 0.04^{\mathrm{D}} / 0.02^{\mathrm{A}} & 0.02^{\mathrm{D}} / 0.01^{\mathrm{A}} & 0.01^{\mathrm{D}} / 0.01^{\mathrm{A}} & 0.08^{\mathrm{D}} / 0.06^{\mathrm{A}}\end{array}$

Note. All $\beta$ values were standardized. SE: standardized error; SD: standard deviation; D: depression; A: anxiety; Bootstrap sample size: 5,000; LLCI: lower limit confidence interval; ULCI: upper limit confidence interval.

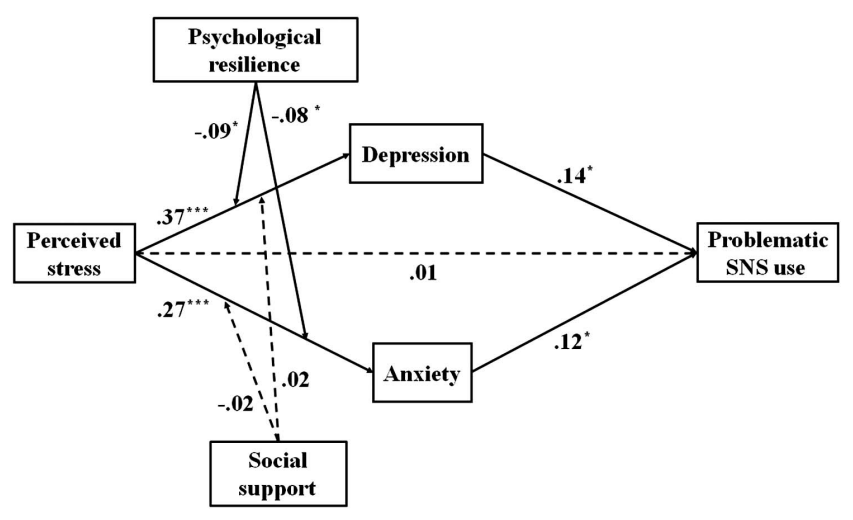

Figure 2. The moderated mediation model

anxiety $(\beta=0.27, p<.001)$, depression and anxiety were positively related to problematic SNS use $(\beta=0.14,0.12$, respectively, $p<.05)$, and perceived stress was not directly related to problematic SNS use $(p>.05)$. These results indicate that depression and anxiety mediated the relationship between perceived stress and problematic SNS use. More concretely, the mediating effects of depression and anxiety were $0.05(0.37 \times 0.14)$ and $0.03(0.27 \times 0.12)$, respectively. The interaction term of perceived stress and psychological resilience was negatively related to depression $(\beta=-0.09, p<.05)$ and anxiety $(\beta=-0.08, p<.05)$, indicating a significant moderating effect of psychological resilience on the relations between perceived stress and depression/anxiety. To facilitate the interpretation of these interaction effects, we followed the recommendations of Cohen, Cohen, West, and Aiken (2003) for plotting the predicted depression and anxiety against perceived stress, separately for low and high levels of psychological resilience (1 $S D$ below and $1 S D$ above the mean, respectively) (see Figures 3 and 4). A simple slope test (Dearing \&

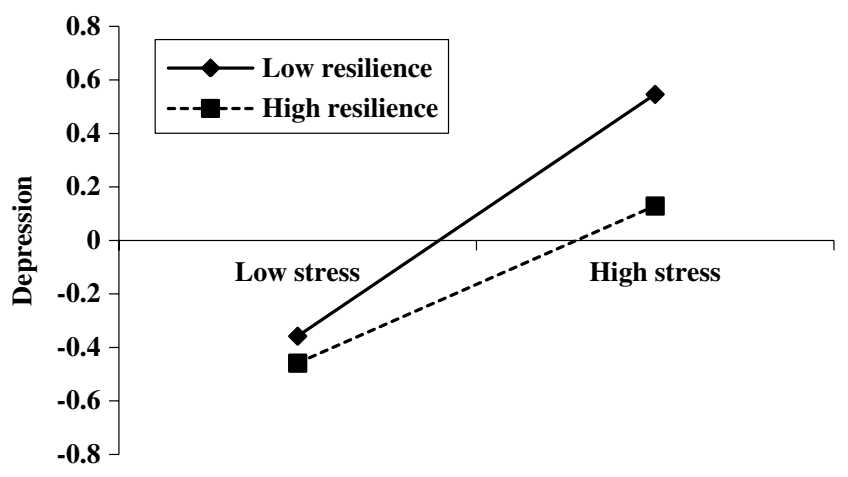

Figure 3. Psychological resilience as a moderator in the relationship between perceived stress and depression

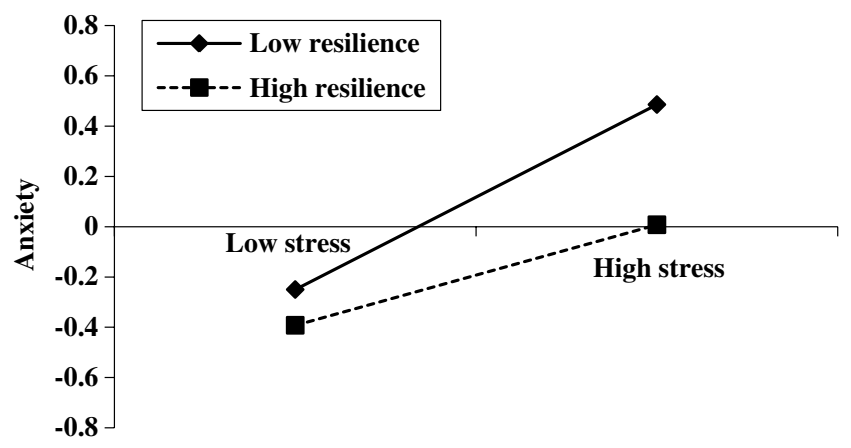

Figure 4. Psychological resilience as a moderator in the relationship between perceived stress and anxiety

Hamilton, 2006) showed that the positive relations between perceived stress and depression/anxiety were statistically significant among respondents with lower levels of psychological resilience $\left(\beta_{\text {Depression }}=0.46, \beta_{\text {Anxiety }}=0.45\right.$, $p<.001$ ), but not for those with higher levels of 
psychological resilience $(p>.05)$. Regarding the interaction term between perceived stress and social support, we did not find a significant interaction effect $(p>.05)$, which suggests that the relations between perceived stress and depression/ anxiety were not moderated by social support.

Further, we analyzed the conditional indirect effect of perceived stress on problematic SNS use. We found that the indirect effects of perceived stress on problematic SNS use via depression and anxiety were significant $\left(\beta_{\text {Depression }}=0.06,95 \% \mathrm{CI}=[0.01,0.12] ; \beta_{\text {Anxiety }}=0.04\right.$, $95 \% \mathrm{CI}=[0.01,0.09])$ for individuals with lower levels of psychological resilience $(M-1 S D)$. The indirect effects between perceived stress and problematic SNS use were significant but weaker $\left(\beta_{\text {Depression }}=0.04,95 \% \mathrm{CI}=\right.$ $\left.[0.01,0.08] ; \beta_{\text {Anxiety }}=0.02,95 \% \mathrm{CI}=[0.01,0.06]\right)$ for users with higher levels of psychological resilience $(M+1 S D)$. These results indicated that the mediating effects of depression and anxiety on the association between perceived stress and problematic SNS use were moderated by psychological resilience. Specifically, the indirect effects of perceived stress on problematic SNS use via depression and anxiety were stronger for individuals with lower level of psychological resilience than those with higher level of psychological resilience.

\section{DISCUSSION AND CONCLUSIONS}

In this study, a moderated mediation model was tested to analyze the mechanism underlying the association between perceived stress and problematic SNS use among Chinese college students. Findings suggest that the mediating effects of depression and anxiety on the association between perceived stress and problematic SNS use were moderated by psychological resilience. Specifically, the mediating effects of depression and anxiety were stronger for students with lower levels of psychological resilience than for those with higher levels of psychological resilience. We next discuss each of our research hypotheses in light of this moderated mediation model of perceived stress and problematic SNS use.

\section{The mediating effects of depression and anxiety}

We found that depression and anxiety mediated the association between perceived stress and problematic SNS usage. This finding supports $H 1$ ( $H 1 a$ and $H 1 b$ ) and is in line with prior research (e.g., Chen et al., 2012; Ketcherside \& Filbey, 2015; Zhao et al., 2017). Our finding is also consistent with the viewpoints of Davis (2001), who believes that stressful life events and a susceptible disposition (e.g., depression and social anxiety) are risky factors for Internet addiction.

Coyne and Downey (1991) hold that stressful life events can lead to emotional problems, including depression and anxiety. Many college students experience multiple stressors, including struggling for independence, problems with roommates or friends, worries about dating, and concerns about grades (Arnett, 2000). When students poorly managed these stressors, they might experience some negative feelings such as loneliness, nervousness, and excessive worrying (Darling, McWey, Howard, \& Olmstead, 2007). Under this situation, college students may choose to use SNS excessively as a way to cope with their negative moods resulting from stress (Brailovskaia \& Margraf, 2017; Ryan et al., 2014). More importantly, the finding supports the compensatory Internet use theory (Kardefelt-Winther, 2014), which holds that individuals with low psychosocial well-being are more likely to rely on Internet for the relief of negative moods. This may lead to overuse of Internet and even addictive symptoms.

\section{The moderating effects of psychological resilience}

We found that psychological resilience moderated the links between perceived stress and depression/anxiety. Compared with students reporting higher psychological resilience, the associations between perceived stress and depression/ anxiety were stronger for those with lower psychological resilience. The finding supports $H 2$ (both $H 2 a$ and $H 2 b$ ) and is in line with previous findings (e.g., Goldstein et al., 2013), suggesting that psychological resilience contributes to protect college students from the adverse outcomes of stress such as depression/anxiety. The finding is also consistent with the protective factor model of resilience (Garmezy et al., 1984) and the resilience-stress theory (Fletcher \& Sarkar, 2013; Masten, 2011), that is, positive personal assets (e.g., psychological resilience and optimism) can reduce the negative impact of stress on individuals' mental health. Empirically, college students with high resilience not only tend to report more positive emotions, but can also use positive emotions to buffer negative emotional experiences (Tugade \& Fredrickson, 2004). It is possible this is why college students with greater psychological resilience reported lower levels of depression and anxiety, which in our model led to less problematic SNS use.

\section{The roles of social support}

Inconsistent with $H 3$ ( $H 3 a$ and $H 3 b$ ), we did not find moderating effects of social support on the relations between perceived stress and depression/anxiety. This is not in line with several previous findings (e.g., Raffaelli et al., 2013; Wang et al., 2014). One possible explanation is that we used general social support rather than support from particular sources. Clearly, these two concepts overlap but are distinct (Pierce, Sarason, \& Sarason, 1991). The stressbuffering effect of social support may vary depending on the particular sources of support that college students perceived (Lee \& Goldstein, 2016). For example, evidence has shown that support from family, but not from friends, buffered the negative effects of stress on depressive symptoms among college students (Crockett et al., 2007). Focusing on three relationship-specific sources of social support (family, friends, and romantic partners) in a sample of undergraduate students, Lee and Goldstein (2016) found that only support from friends buffered the association between stress and loneliness. Moreover, only support from family, friends, and faculty provides a protective function for college students against stress (Bland, Melton, Welle, \& Bigham, 2012). Conversely, as for general social support, researcher did not find a buffering role of general social support on college students' mental health (e.g., Sherry, Law, Hewitt, Flett, \& Besser, 2008). Our findings might suggest that research 
focusing on social support and its impacts on well-being among college students should assess relationship-specific sources of support.

Despite the non-significant moderating effects of social support, we found significant main effects of social support on depression and anxiety, which is consistent with previous findings (e.g., Raffaelli et al., 2013; Sperry \& Widom, 2013; Wright et al., 2014), and in line with the main effect model of social support. According to the main effect model of social support, social support is directly and negatively associated with psychological distress regardless of whether a person has experienced a stressor (Cohen \& Wills, 1985).

\section{Implications and limitations}

Previous studies have increasingly focused on the contribution of perceived stress to the development of college students' problematic SNS use, but little is known about how and when this risk effect occurs. This study used a moderated mediation analysis to investigate the possible mediating roles of depression/anxiety and moderating roles of psychological resilience and social support between perceived stress and problematic SNS use to better understand the mechanism (how) and context (when) of this risk effect. The results showed that depression and anxiety mediated the association between perceived stress and problematic SNS use and these mediated paths were moderated by psychological resilience. In particular, psychological resilience moderated the positive effects between perceived stress and depression/anxiety. The current findings offer a better understanding of those who are at high risk of problematic SNS use and of the factors that should be targeted by efforts to prevent the development of problematic SNS use in college students with stress. Moreover, these findings highlight the significance of psychological resilience. Many prior intervention studies related to resilience (e.g., Dolbier, Jaggars, \& Steinhardt, 2010; Houston et al., 2017) have confirmed that resilience is a promising candidate for interventions designed to reduce emotional problems and improve outcomes for college students with stress. This suggests that we can decrease the occurrence of problematic SNS use by enhancing college students' psychological resilience.

We should outline some limitations in this study and avenues for future research. First, a survey-based correlational design is hardly able to ascertain the direction of effects among perceived stress, depression/anxiety, and problematic SNS use, but the direction of effects we tested is in line with the previous theoretical and empirical research. Nevertheless, to establish cause, future research needs to validate the moderated mediation mechanism of this study through longitudinal design for data collection. Second, as mentioned above, we only examined the possible moderating role of general social support. Future studies could distinguish friend support, family support, and other types of support. Moreover, this study relied on self-report measures. Future studies could employ multiple informants (e.g., peers and parents) and/or multiple methods (e.g., standardized interview and observation) to collect data, thereby providing more accurate and detailed information. Meanwhile, regression-based PROCESS cannot control measurement error such that structural equation modeling method is encouraged in future research to replicate the results in this study. In addition, our findings are most relevant to the Chinese College students who participated in this study and WeChat as an indicative example of SNS. Future studies could focus on different populations and social network platforms in order to test the transferability of the validated model, which was tested in this study. Last, but not least, it is important to take into consideration other mediators linked to the variables that may have additionally influenced the college students' perceived stress and problematic SNS use. For instance, perceived stress could negatively predict emotional intelligence (Mitra et al., 2018). Internet addiction (Hamissi, Babaie, Hosseini, \& Babaie, 2013) and online gaming addiction (Che et al., 2017) were negatively predicted by emotional intelligence. Hence, emotional intelligence may be a mediator in the relationship between perceived stress and problematic SNS use, which could be tested in the future. Moreover, optimism, cognitive flexibility, and coping style (Southwick, Vythilingam, \& Charney, 2005) are important protective factors that may play a key role in the protection of mental health in stressful situations. Similarly, Plante et al. (2018) recently found that using video games as a coping strategy when stressed predicts increased problematic gaming symptoms, above and beyond other negative coping strategies. Therefore, future research could examine the functions of these variables in the mechanisms underlying the relationship between perceived stress and problematic SNS use.

In conclusion, the results of this study can contribute to a better understanding of how and when perceived stress increases the risk of problematic SNS use, suggesting that the importance of enhancing psychological resilience in preventing problematic SNS use.

Funding sources: This study was supported by the Fundamental Research Funds for the Central Universities (no. SWU1909224).

Authors' contribution: J-LW contributed to study concept and design. X-LH contributed to data collection and wrote the manuscript. H-ZW contributed to data collection and study supervision. T-QH and JG contributed to statistical analysis and interpretation of data. DAG contributed to study supervision and paper proofreading.

Conflict of interest: The authors declare no conflict of interest.

\section{REFERENCES}

Anastasiades, M. H., Kapoor, S., Wootten, J., \& Lamis, D. A. (2017). Perceived stress, depressive symptoms, and suicidal ideation in undergraduate women with varying levels of mindfulness. Archives of Women's Mental Health, 20(1), 129-138. doi:10.1007/s00737-016-0686-5

Anyan, F., \& Hjemdal, O. (2016). Adolescent stress and symptoms of anxiety and depression: Resilience explains and differentiates 
the relationships. Journal of Affective Disorders, 203, 213-220. doi:10.1016/j.jad.2016.05.031

Arnett, J. J. (2000). Emerging adulthood: A theory of development from the late teens through the twenties. American Psychologist, 55(5), 469-480. doi:10.1037/0003-066X.55.5.469

Arslan, G. (2016). Psychological maltreatment, emotional and behavioral problems in adolescents: The mediating role of resilience and self-esteem. Child Abuse \& Neglect, 52, 200-209. doi:10.1016/j.chiabu.2015.09.010

Beutel, M. E., Tibubos, A. N., Klein, E. M., Schmutzer, G., Reiner, I., Kocalevent, R. D., \& Brähler, E. (2017). Childhood adversities and distress - The role of resilience in a representative sample. PLoS One, 12(3), e0173826. doi:10.1371/journal. pone. 0173826

Bland, H. W., Melton, B. F., Welle, P., \& Bigham, L. (2012). Stress tolerance: New challenges for millennial college students. College Student Journal, 46(2), 362-375. doi:10.1037/ t39417-000

Blaxton, J. M., \& Bergeman, C. S. (2017). A process-oriented perspective examining the relationships among daily coping, stress, and affect. Personality and Individual Differences, 104, 357-361. doi:10.1016/j.paid.2016.08.041

Borjalilu, S., Mohammadi, A., \& Mojtahedzadeh, R. (2015). Sources and severity of perceived stress among Iranian medical students. Iranian Red Crescent Medical Journal, 17(10), e17767. doi:10.5812/ircmj.17767

Brailovskaia, J., \& Margraf, J. (2017). Facebook Addiction Disorder (FAD) among German students - A longitudinal approach. PLoS One, 12(12), e0189719. doi:10.1371/journal.pone.0189719

Brailovskaia, J., Schillack, H., \& Margraf, J. (2018). Facebook Addiction Disorder in Germany. Cyberpsychology, Behavior, and Social Networking, 21(7), 450-456. doi:10.1089/cyber. 2018.0140

Brailovskaia, J., Teismann, T., \& Margraf, J. (2018). Physical activity mediates the association between daily stress and Facebook Addiction Disorder (FAD) - A longitudinal approach among German students. Computers in Human Behavior, 86, 199-204. doi:10.1016/j.chb.2018.04.045

Breslau, N., Novak, S. P., \& Kessler, R. C. (2004). Psychiatric disorders and stages of smoking. Biological Psychiatry, 55(1), 69-76. doi:10.1016/S0006-3223(03)00317-2

Bujarski, S., \& Ray, L. A. (2014). Negative affect is associated with alcohol, but not cigarette use in heavy drinking smokers. Addictive Behaviors, 39(12), 1723-1729. doi:10.1016/j. addbeh.2014.07.019

Campbell-Sills, L., Cohan, S. L., \& Stein, M. B. (2006). Relationship of resilience to personality, coping, and psychiatric symptoms in young adults. Behaviour Research and Therapy, 44(4), 585-599. doi:10.1016/j.brat.2005.05.001

Che, D., Hu, J., Zhen, S., Yu, C., Li, B., Chang, X., \& Zhang, W. (2017). Dimensions of emotional intelligence and online gaming addiction in adolescence: The indirect effects of two facets of perceived stress. Frontiers in Psychology, 8, 1664-1078. doi:10.3389/fpsyg.2017.01206

Chen, J., Wang, Z., Guo, B., Arcelus, J., Zhang, H., Jia, X., Xu, Y., Qiu, J., Xiao, Z., \& Yang, M. (2012). Negative affect mediates effects of psychological stress on disordered eating in young Chinese women. PLoS One, 7(10), e46878. doi:10.1371/ journal.pone. 0046878

Chen, Z., Poon, K. T., \& Cheng, C. (2017). Deficits in recognizing disgust facial expressions and Internet addiction: Perceived stress as a mediator. Psychiatry Research, 254, 211-217. doi:10.1016/j.psychres.2017.04.057

Çivitci, A. (2015). The moderating role of positive and negative affect on the relationship between perceived social support and stress in college students. Educational Sciences: Theory and Practice, 15, 565-573. doi:10.12738/estp.2015.3.2553

Cohen, J., Cohen, P., West, S. G., \& Aiken, L. S. (2003). Applied multiple regression/correlation analysis for the behavioral sciences. Mahwah, NJ: Lawrence Erlbaum Associates.

Cohen, S. (1988). Psychosocial models of the role of social support in the etiology of physical disease. Health Psychology, 7(3), 269-297. doi:10.1037/0278-6133.7.3.269

Cohen, S. (2004). Social relationships and health. American Psychologist, 59(8), 676-684. doi:10.1037/0003-066X.59.8.676

Cohen, S., Kamarck, T., \& Mermelstein, R. (1983). A global measure of perceived stress. Journal of Health and Social Behavior, 24(4), 385-396. doi:10.2307/2136404

Cohen, S., Underwood, L. G., \& Gottlieb, B. H. (Eds.). (2000). Social support measurement and intervention: A guide for health and social scientists. Oxford, UK: Oxford University Press.

Cohen, S., \& Wills, T. A. (1985). Stress, social support, and the buffering hypothesis. Psychological Bulletin, 98(2), 310-357. doi:10.1037/0033-2909.98.2.310

Cole, M. S., Walter, F., \& Bruch, H. (2008). Affective mechanisms linking dysfunctional behavior to performance in work teams: A moderated mediation study. Journal of Applied Psychology, 93(5), 945-958. doi:10.1037/0021-9010.93.5.945

Cole, N. N., Nonterah, C. W., Utsey, S. O., Hook, J. N., Hubbard, R. R., Opare-Henaku, A., \& Fischer, N. L. (2015). Predictor and moderator effects of ego resilience and mindfulness on the relationship between academic stress and psychological wellbeing in a sample of Ghanaian college students. Journal of Black Psychology, 41(4), 340-357. doi:10.1177/00957984 14537939

Collishaw, S., Pickles, A., Messer, J., Rutter, M., Shearer, C., \& Maughan, B. (2007). Resilience to adult psychopathology following childhood maltreatment: Evidence from a community sample. Child Abuse \& Neglect, 31(3), 211-229. doi:10. 1016/j.chiabu.2007.02.004

Connor, K. M., \& Davidson, J. R. T. (2003). Development of a new resilience scale: The Connor-Davidson Resilience Scale (CDRISC). Depression and Anxiety, 18(2), 76-82. doi:10.1002/ da. 10113

Coyne, J. C., \& Downey, G. (1991). Social factors and psychopathology: Stress, social support, and coping processes. Annual Review of Psychology, 42(1), 401-425. doi:10.1146/annurev. ps.42.020191.002153

Crockett, L. J., Iturbide, M. I., Torres Stone, R. A., McGinley, M., Raffaelli, M., \& Carlo, G. (2007). Acculturative stress, social support, and coping: Relations to psychological adjustment among Mexican American college students. Cultural Diversity and Ethnic Minority Psychology, 13(4), 347-355. doi:10.1037/ 1099-9809.13.4.347

Curran, P. J., West, S. G., \& Finch, J. F. (1996). The robustness of test statistics to nonnormality and specification error in confirmatory factor analysis. Psychological Methods, 1(1), 16-29. doi:10.1037/1082-989X.1.1.16

Darling, C. A., McWey, L. M., Howard, S. N., \& Olmstead, S. B. (2007). College student stress: The influence of interpersonal relationships on sense of coherence. Stress and Health, 23(4), 215-229. doi:10.1002/smi.1139 
Davis, R. A. (2001). A cognitive-behavioral model of pathological Internet use. Computers in Human Behavior, 17(2), 187-195. doi:10.1016/S0747-5632(00)00041-8

Dearing, E., \& Hamilton, L. C. (2006). Contemporary advances and classic advice for analyzing mediating and moderating variables. Monographs of the Society for Research in Child Development, 71, 88-104. doi:10.1111/j.1540-5834.2006. 00406.x

Dolbier, C. L., Jaggars, S. S., \& Steinhardt, M. A. (2010). Stressrelated growth: Pre-intervention correlates and change following a resilience intervention. Stress and Health, 26(2), 135-147. doi: $10.1002 /$ smi. 1275

Edwards, J. R., \& Lambert, L. S. (2007). Methods for integrating moderation and mediation: A general analytical framework using moderated path analysis. Psychological Methods, 12(1), 1-22. doi:10.1037/1082-989X.12.1.1

Elphinston, R. A., \& Noller, P. (2011). Time to face it! Facebook intrusion and the implications for romantic jealousy and relationship satisfaction. Cyberpsychology, Behavior, and Social Networking, 14(11), 631-635. doi:10.1089/cyber.2010.0318

Fletcher, D., \& Sarkar, M. (2013). Psychological resilience: A review and critique of definitions, concepts, and theory. European Psychologist, 18(1), 12-23. doi:10.1027/1016-9040/a000124

Garmezy, N., Masten, A. S., \& Tellegen, A. (1984). The study of stress and competence in children: A building block for developmental psychopathology. Child Development, 55(1), 97-111. doi:10.2307/1129837

Goldstein, A. L., Faulkner, B., \& Wekerle, C. (2013). The relationship among internal resilience, smoking, alcohol use, and depression symptoms in emerging adults transitioning out of child welfare. Child Abuse \& Neglect, 37(1), 22-32. doi:10.1016/j.chiabu.2012.08.007

Gonzales, A. L., \& Hancock, J. T. (2011). Mirror, mirror on my Facebook wall: Effects of exposure to Facebook on selfesteem. Cyberpsychology, Behavior, and Social Networking, 14(1-2), 79-83. doi:10.1089/cyber.2009.0411

Hamissi, J., Babaie, M., Hosseini, M., \& Babaie, F. (2013). The relationship between emotional intelligence and technology addiction among university students. International Journal of Collaborative Research on Internal Medicine \& Public Health, 5(5), 310-319.

Hayes, A. F. (2013). Introduction to mediation, moderation, and conditional process analysis: A regression-based approach. New York, NY: Guilford Press.

Heinen, I., Bullinger, M., \& Kocalevent, R. D. (2017). Perceived stress in first year medical students - Associations with personal resources and emotional distress. BMC Medical Education, 17(1), 4. doi:10.1186/s12909-016-0841-8

Hong, F. Y., Chiu, S. I., \& Huang, D. H. (2012). A model of the relationship between psychological characteristics, mobile phone addiction and use of mobile phones by Taiwanese university female students. Computers in Human Behavior, 28(6), 2152-2159. doi:10.1016/j.chb.2012.06.020

Hou, X. L., Wang, H. Z., Guo, C., Gaskin, J., Rost, D. H., \& Wang, J. L. (2017). Psychological resilience can help combat the effect of stress on problematic social networking site usage. Personality and Individual Differences, 109, 61-66. doi:10. 1016/j.paid.2016.12.048

Houston, J. B., First, J., Spialek, M. L., Sorenson, M. E., MillsSandoval, T., Lockett, M., First, N. L., Nitiéma, P., Allen, S. F., $\&$ Pfefferbaum, B. (2017). Randomized controlled trial of the
Resilience and Coping Intervention (RCI) with undergraduate university students. Journal of American College Health, 65(1), 1-9. doi:10.1080/07448481.2016.1227826

Hu, T., Zhang, D., \& Wang, J. (2015). A meta-analysis of the trait resilience and mental health. Personality and Individual Differences, 76, 18-27. doi:10.1016/j.paid.2014.11.039

Huang, L. Y., Hsieh, Y. J., \& Wu, Y. C. J. (2014). Gratifications and social network service usage: The mediating role of online experience. Information \& Management, 51(6), 774-782. doi:10.1016/j.im.2014.05.004

Kardefelt-Winther, D. (2014). A conceptual and methodological critique of Internet addiction research: Towards a model of compensatory Internet use. Computers in Human Behavior, 31, 351-354. doi:10.1016/j.chb.2013.10.059

Kelley, K. J., \& Gruber, E. M. (2010). Psychometric properties of the Problematic Internet Use Questionnaire. Computers in Human Behavior, 26(6), 1838-1845. doi:10.1016/j.chb.2010.07.018

Kendall, P. C., Kortlander, E., Chansky, T. E., \& Brady, E. U. (1992). Comorbidity of anxiety and depression in youth: Treatment implications. Journal of Consulting and Clinical Psychology, 60(6), 869-880. doi:10.1037/0022-006X.60. 6.869

Ketcherside, A., \& Filbey, F. M. (2015). Mediating processes between stress and problematic marijuana use. Addictive Behaviors, 45, 113-118. doi:10.1016/j.addbeh.2015.01.015

Klink, J. L., Byars-Winston, A., \& Bakken, L. L. (2008). Coping efficacy and perceived family support: Potential factors for reducing stress in premedical students. Medical Education, 42(6), 572-579. doi:10.1111/j.1365-2923.2008.03091.x

Kumar, U., \& Singh, R. (2014). Resilience and spirituality as predictors of psychological well-being among university students. Journal of Psychosocial Research, 9, 227-235.

Kuss, D. J., \& Griffiths, M. D. (2011). Online social networking and addiction - A review of the psychological literature. International Journal of Environmental Research and Public Health, 8(9), 3528-3552. doi:10.3390/ijerph8093528

Lee, C. Y. S., \& Goldstein, S. E. (2016). Loneliness, stress, and social support in young adulthood: Does the source of support matter? Journal of Youth and Adolescence, 45(3), 568-580. doi:10.1007/s10964-015-0395-9

Li, Y. H., Wang, R., Lu, X. H., Wang, X. J., \& Zhu, J. (2016). Report and investigation model of WeChat popularization in China's colleges and universities in 2015. Paper presented at Proceedings of the 2016 International Conference on Intelligent Control and Computer Application. Atlantis Press, Paris, France. Retrieved from https://www.researchgate.net/publication/ 319699975_Report_and_investigation_model_of_WeChat_ popularization_in_China's_colleges_and_universities_in_2015

Masten, A. S. (2011). Resilience in children threatened by extreme adversity: Frameworks for research, practice, and translational synergy. Development and Psychopathology, 23(2), 493-506. doi:10.1017/S0954579411000198

McKenzie, M., Olsson, C. A., Jorm, A. F., Romaniuk, H., \& Patton, G. C. (2010). Association of adolescent symptoms of depression and anxiety with daily smoking and nicotine dependence in young adulthood: Findings from a 10-year longitudinal study. Addiction, 105(9), 1652-1659. doi:10.1111/ j.1360-0443.2010.03002.x

Min, J. A., Lee, C. U., \& Chae, J. H. (2015). Resilience moderates the risk of depression and anxiety symptoms on suicidal ideation in patients with depression and/or anxiety disorders. 
Comprehensive Psychiatry, 56, 103-111. doi:10.1016/j. comppsych.2014.07.022

Min, J. A., Yoon, S., Lee, C. U., Chae, J. H., Lee, C., Song, K. Y., \& Kim, T. S. (2013). Psychological resilience contributes to low emotional distress in cancer patients. Supportive Care in Cancer, 21(9), 2469-2476. doi:10.1007/s00520-013-1807-6

Mitra, S., Sarkar, A. P., Haldar, D., Saren, A. B., Lo, S., \& Sarkar, G. N. (2018). Correlation among perceived stress, emotional intelligence, and burnout of resident doctors in a medical college of West Bengal: A mediation analysis. Indian Journal of Public Health, 62, 27-31. doi:10.4103/ijph.IJPH_368_16

Muller, D., Judd, C. M., \& Yzerbyt, V. Y. (2005). When moderation is mediated and mediation is moderated. Journal of Personality and Social Psychology, 89(6), 852-863. doi:10.1037/0022-3514.89.6.852

Ndasauka, Y., Hou, J., Wang, Y., Yang, L., Yang, Z., Ye, Z., \& Zhang, X. (2016). Excessive use of Twitter among college students in the UK: Validation of the Microblog Excessive Use Scale and relationship to social interaction and loneliness. Computers in Human Behavior, 55, 963-971. doi:10.1016/ j.chb.2015.10.020

Osborne, J. W., \& Overbay, A. (2004). The power of outliers (and why researchers should always check for them). Practical Assessment, Research \& Evaluation, 9, 1-12.

Park, J., Kitayama, S., Karasawa, M., Curhan, K., Markus, H. R., Kawakami, N., Miyamoto, Y., Love, G. D., Coe, C. L., \& Ryff, C. D. (2013). Clarifying the links between social support and health: Culture, stress, and neuroticism matter. Journal of Health Psychology, 18(2), 226-235. doi:10.1177/135910 5312439731

Peng, J. X., Yang, Q. W., \& Luo, Y. J. (2013). Selected attentional bias in different level of trait anxiety. Acta Psychologica Sinica, 45, 1085-1093.

Pierce, G. R., Sarason, I. G., \& Sarason, B. R. (1991). General and relationship-based perceptions of social support: Are two constructs better than one? Journal of Personality and Social Psychology, 61(6), 1028-1039. doi:10.1037/0022-3514.61. 6.1028

Plante, C. N., Gentile, D. A., Groves, C. L., Modlin, A., \& BlancoHerrera, J. (2018). Video games as coping mechanisms in the etiology of video game addiction. Psychology of Popular Media Culture. Advance online publication. doi:10.1037/ppm0000186

Radloff, L. S. (1977). The CES-D Scale: A self-report depression scale for research in the general population. Applied Psychological Measurement, 1(3), 385-401. doi:10.1177/01466216 7700100306

Raffaelli, M., Andrade, F. C. D., Wiley, A. R., Sanchez-Armass, O., Edwards, L. L., \& Aradillas-Garcia, C. (2013). Stress, social support, and depression: A test of the stress-buffering hypothesis in a Mexican sample. Journal of Research on Adolescence, 23(2), 283-289. doi:10.1111/jora.12006

Roberts, R. E., Andrews, J. A., Lewinsohn, P. M., \& Hops, H. (1990). Assessment of depression in adolescents using the Center for Epidemiologic Studies Depression Scale. Psychological Assessment: A Journal of Consulting and Clinical Psychology, 2(2), 122-128. doi:10.1037/1040-3590.2.2.122

Ryan, T., Chester, A., Reece, J., \& Xenos, S. (2014). The uses and abuses of Facebook: A review of Facebook addiction. Journal of Behavioral Addictions, 3(3), 133-148. doi:10.1556/JBA.3. 2014.016

Samaha, M., \& Hawi, N. S. (2016). Relationships among smartphone addiction, stress, academic performance, and satisfaction with life. Computers in Human Behavior, 57, 321-325. doi:10.1016/j.chb.2015.12.045

Satici, S. A., \& Uysal, R. (2015). Well-being and problematic Facebook use. Computers in Human Behavior, 49, 185-190. doi:10.1016/j.chb.2015.03.005

Schradle, S. B., \& Dougher, M. J. (1985). Social support as a mediator of stress: Theoretical and empirical issues. Clinical Psychology Review, 5(6), 641-661. doi:10.1016/02727358(85)90039-X10.1016/0272-7358(85)90039-X

Sherry, S. B., Law, A., Hewitt, P. L., Flett, G. L., \& Besser, A. (2008). Social support as a mediator of the relationship between perfectionism and depression: A preliminary test of the social disconnection model. Personality and Individual Differences, 45(5), 339-344. doi:10.1016/j.paid.2008.05.001

Smith, B. W., Tooley, E. M., Christopher, P. J., \& Kay, V. S. (2010). Resilience as the ability to bounce back from stress: A neglected personal resource? The Journal of Positive Psychology, 5(3), 166-176. doi:10.1080/17439760.2010.482186

Song, H., Zmyslinski-Seelig, A., Kim, J., Drent, A., Victor, A., Omori, K., \& Allen, M. (2014). Does Facebook make you lonely? A meta analysis. Computers in Human Behavior, 36, 446-452. doi:10.1016/j.chb.2014.04.011

Southwick, S. M., Vythilingam, M., \& Charney, D. S. (2005). The psychobiology of depression and resilience to stress: Implications for prevention and treatment. Annual Review of Clinical Psychology, 1(1), 255-291. doi:10.1146/annurev.clinpsy.1. 102803.143948

Sperry, D. M., \& Widom, C. S. (2013). Child abuse and neglect, social support, and psychopathology in adulthood: A prospective investigation. Child Abuse \& Neglect, 37(6), 415-425. doi:10.1016/j.chiabu.2013.02.006

Spielberger, C. D., Gorsuch, R. L., \& Lushene, R. E. (1970). Manual for the State-Trait Anxiety Inventory. Palo Alto, CA: Consulting Psychologists Press.

Thoits, P. A. (2011). Mechanisms linking social ties and support to physical and mental health. Journal of Health and Social Behavior, 52(2), 145-161. doi:10.1177/002214 6510395592

Tugade, M. M., \& Fredrickson, B. L. (2004). Resilient individuals use positive emotions to bounce back from negative emotional experiences. Journal of Personality and Social Psychology, 86(2), 320-333. doi:10.1037/0022-3514.86.2.320

Turel, O., \& Qahri-Saremi, H. (2016). Problematic use of social networking sites: Antecedents and consequence from a dualsystem theory perspective. Journal of Management Information Systems, 33(4), 1087-1116. doi:10.1080/07421222. 2016.1267529

Wallace, D. D., Boynton, M. H., \& Lytle, L. A. (2017). Multilevel analysis exploring the links between stress, depression, and sleep problems among two-year college students. Journal of American College Health, 65(3), 187-196. doi:10.1080/ 07448481.2016.1269111

Wang, J. L., Jackson, L. A., Gaskin, J., \& Wang, H. Z. (2014). The effects of social networking site (SNS) use on college students' friendship and well-being. Computers in Human Behavior, 37, 229-236. doi:10.1016/j.chb.2014.04.051

Wang, P., Zhao, M., Wang, X., Xie, X., Wang, Y., \& Lei, L. (2017). Peer relationship and adolescent smartphone addiction: The mediating role of self-esteem and the moderating role of the need to belong. Journal of Behavioral Addictions, 6(4), 708-717. doi:10.1556/2006.6.2017.079 
Wang, X., Cai, L., Qian, J., \& Peng, J. (2014). Social support moderates stress effects on depression. International Journal of Mental Health Systems, 8(1), 41. doi:10.1186/1752-4458-8-41

Watson, D., \& Clark, L. A. (1984). Negative affectivity: The disposition to experience aversive emotional states. Psychological Bulletin, 96(3), 465-490. doi:10.1037/0033-2909.96.3.465

Watson, D., \& Pennebaker, J. W. (1989). Health complaints, stress, and distress: Exploring the central role of negative affectivity. Psychological Review, 96(2), 234-254. doi:10.1037/0033295X.96.2.234

Watson, D., Weber, K., Assenheimer, J. S., Clark, L. A., Strauss, M. E., \& McCormick, R. A. (1995). Testing a tripartite model: I. Evaluating the convergent and discriminant validity of anxiety and depression symptom scales. Journal of Abnormal Psychology, 104(1), 3-14. doi:10.1037/0021-843X.104.1.3

Wright, K. B., King, S., \& Rosenberg, J. (2014). Functions of social support and self-verification in association with loneliness, depression, and stress. Journal of Health Communication, 19(1), 82-99. doi:10.1080/10810730.2013.798385

Wu, A., Cheung, V., Ku, L., \& Hung, E. (2013). Psychological risk factors of addiction to social networking sites among Chinese smartphone users. Journal of Behavioral Addictions, 2(3), 160-166. doi:10.1556/JBA.2.2013.006

Wu, Y. L., Zhao, X., Ding, X. X., Yang, H. Y., Qian, Z. Z., Feng, F., Lu, S. S., Hu, C. Y., Gong, F. F., \& Sun, Y. H. (2017). A prospective study of psychological resilience and depression among left-behind children in China. Journal of Health Psychology, 22(5), 627-636. doi:10.1177/1359105315610811

Yu, X., \& Zhang, J. (2007). Factor analysis and psychometric evaluation of the Connor-Davidson Resilience Scale (CDRISC) with Chinese people. Social Behavior and Personality: An International Journal, 35(1), 19-30. doi:10.2224/sbp. 2007.35.1.19

Zhao, F., Zhang, Z. H., Bi, L., Wu, X. S., Wang, W. J., Li, Y. F., \& Sun, Y. H. (2017). The association between life events and Internet addiction among Chinese vocational school students: The mediating role of depression. Computers in Human Behavior, 70, 30-38. doi:10.1016/j.chb.2016.12.057

Zimet, G. D., Dahlem, N. W., Zimet, S. G., \& Farley, G. K. (1988). The multidimensional scale of perceived social support. Journal of Personality Assessment, 52(1), 30-41. doi:10.1207/ s15327752jpa5201_2 